Supplement of The Cryosphere, 9, 399-409, 2015

http://www.the-cryosphere.net/9/399/2015/

doi:10.5194/tc-9-399-2015-supplement

(C) Author(s) 2015. CC Attribution 3.0 License.

(c) (i)

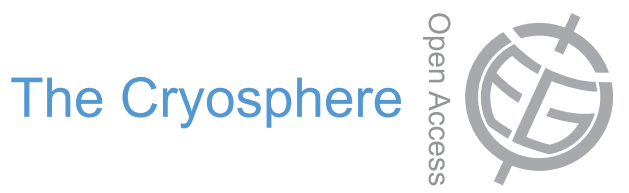

Supplement of

\title{
Assessment of sea ice simulations in the CMIP5 models
}

Q. Shu et al.

Correspondence to: F. Qiao (qiaofl@ fio.org.cn) 


\section{Supplementary material}
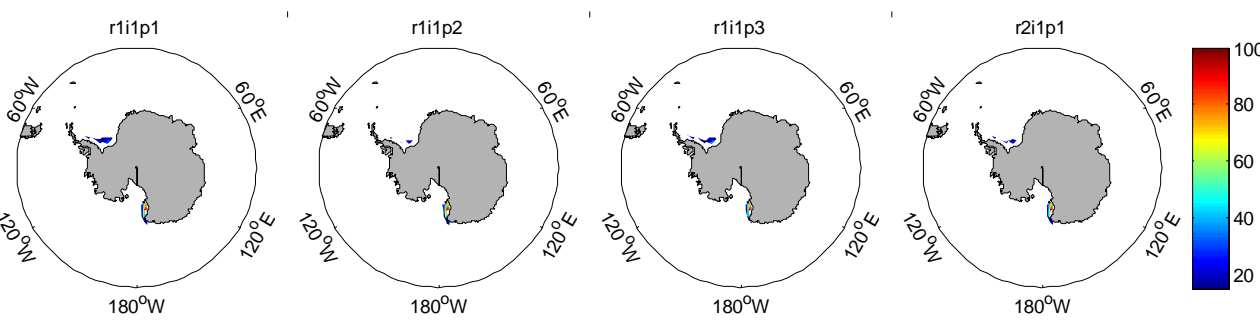

2
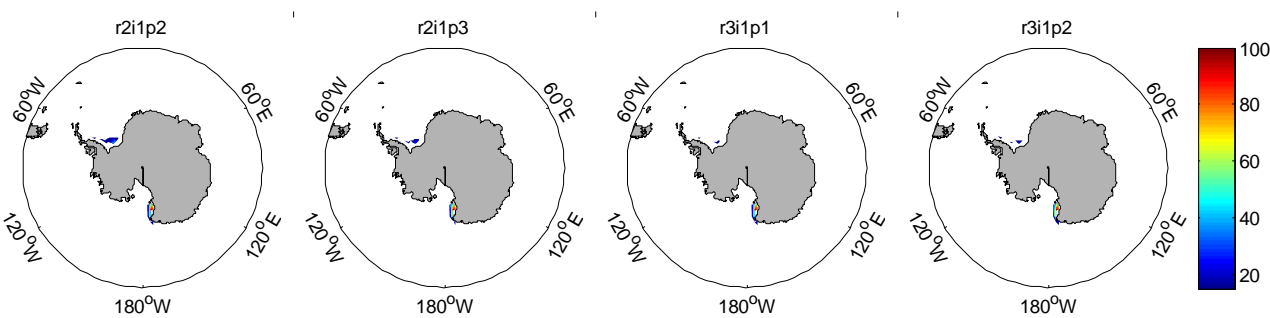

3

r3i1p3

r4i1p1

r4i1p2

r4i1p3
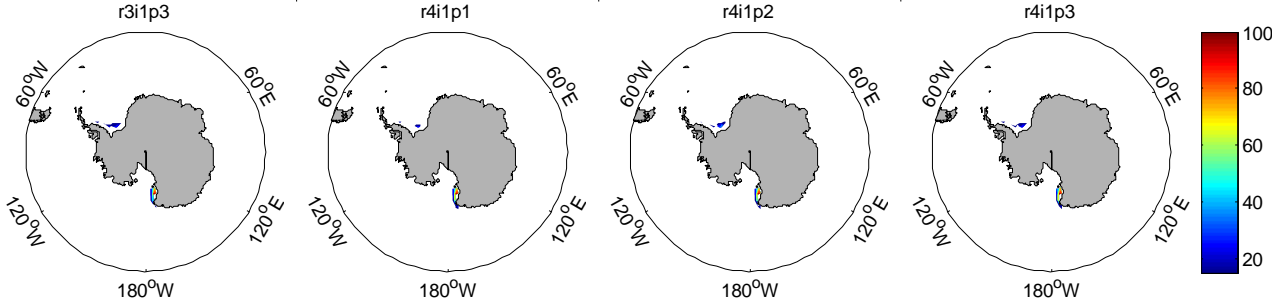

4
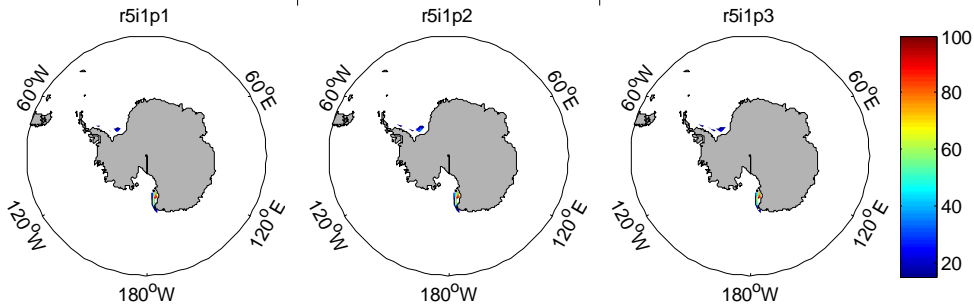

5

6 Figure S1. GISS-E2-R different ensemble realizations simulated Antarctic sea ice

7 concentration in February during 1979-2005 (units: \%).

8 

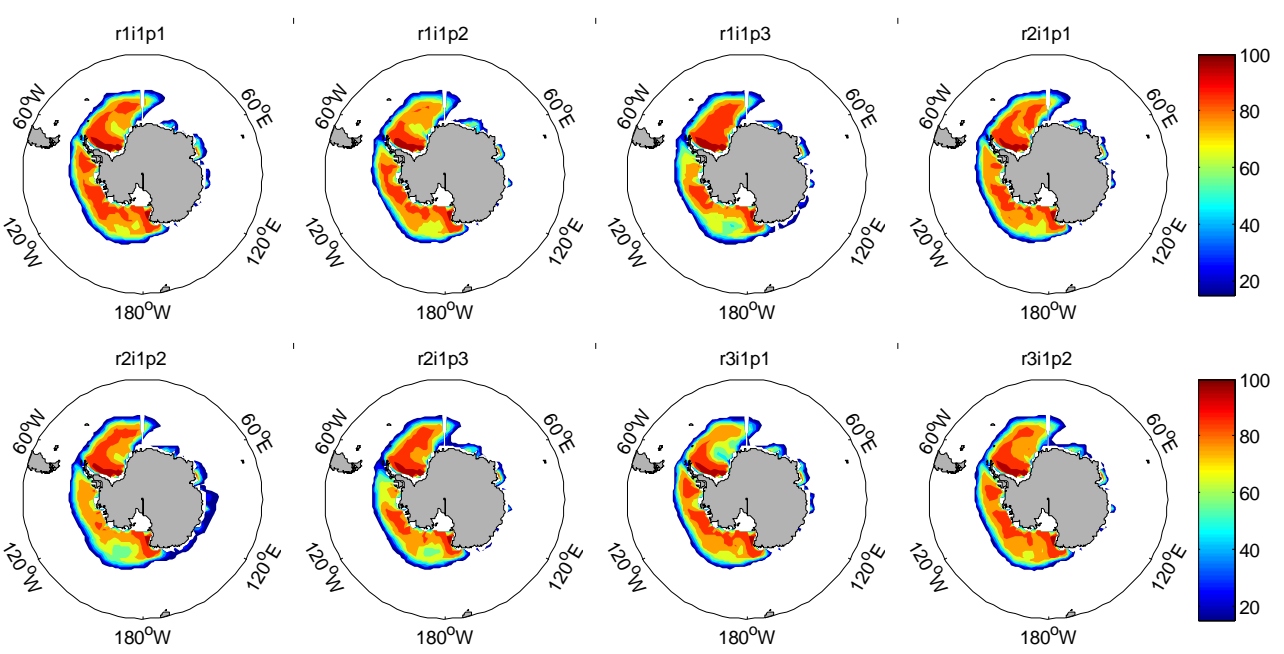

10
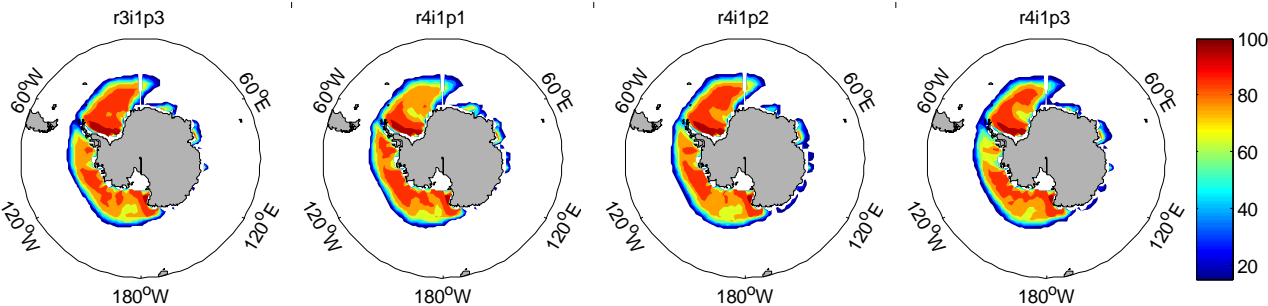

11

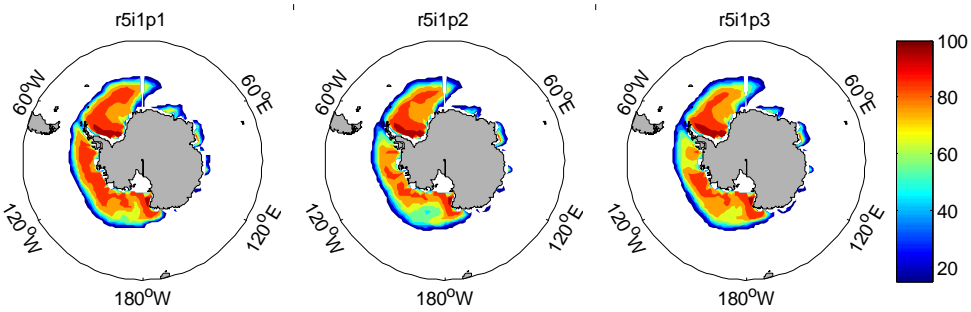

12

13

14

15

Figure S2. GISS-E2-R different ensemble realizations simulated Antarctic sea ice concentration in September during 1979-2005 (units: \%). 


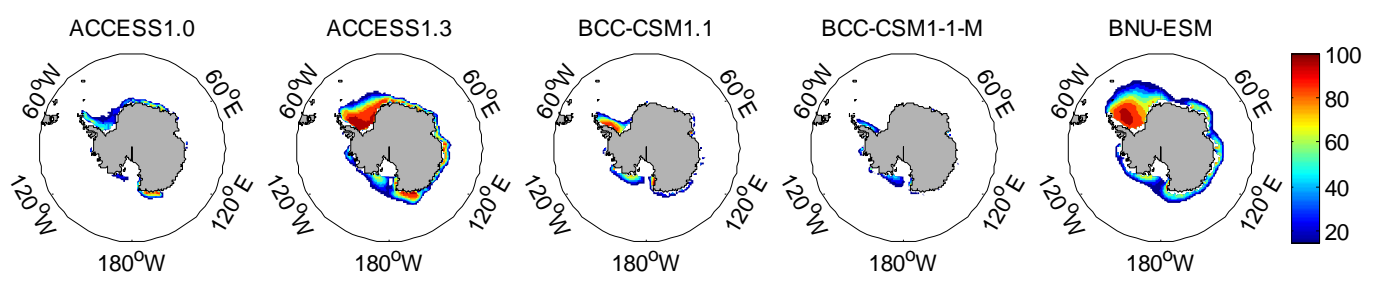

17
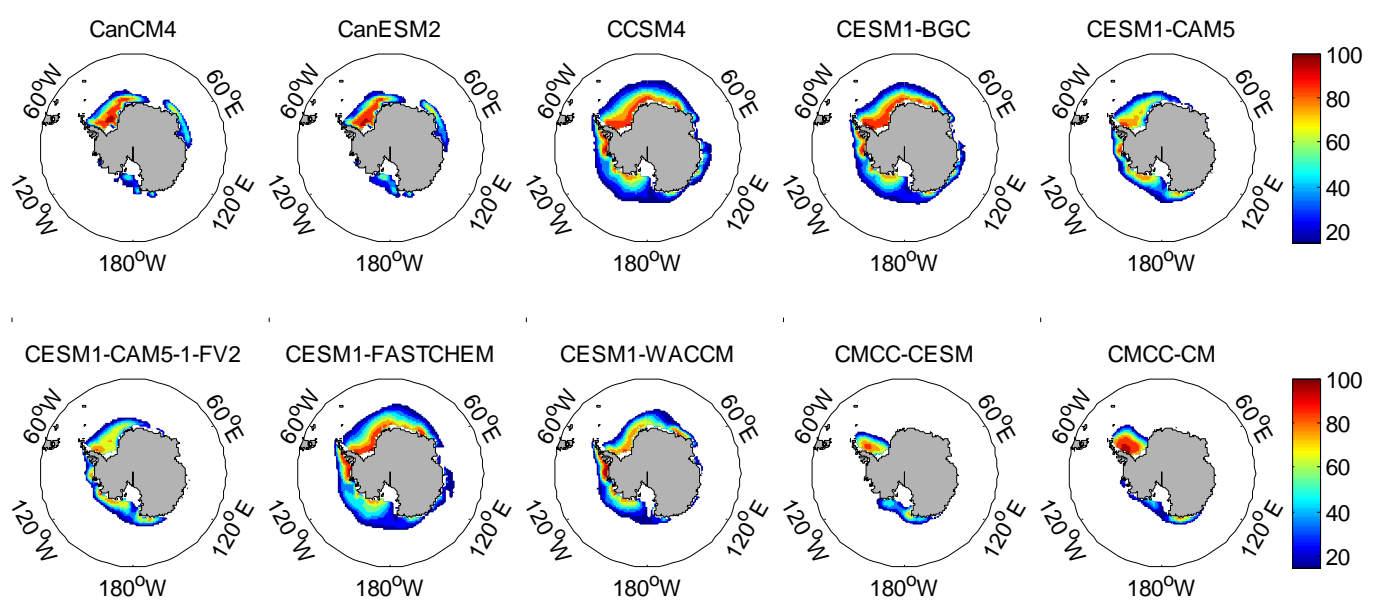

18

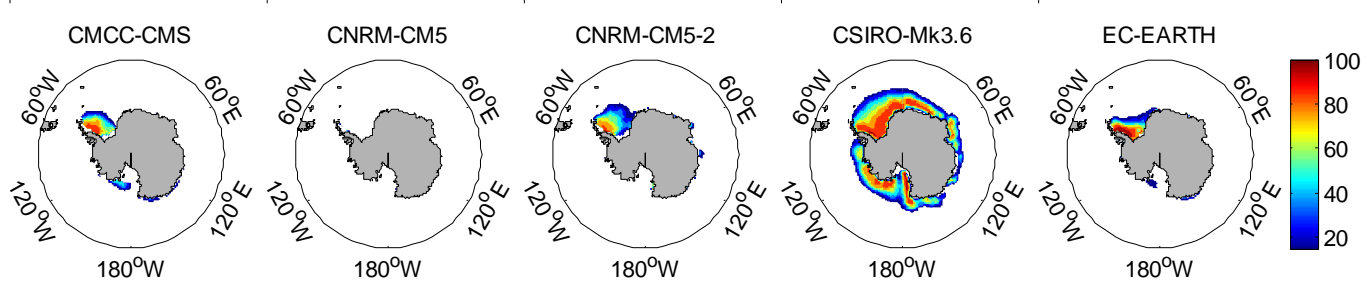

19

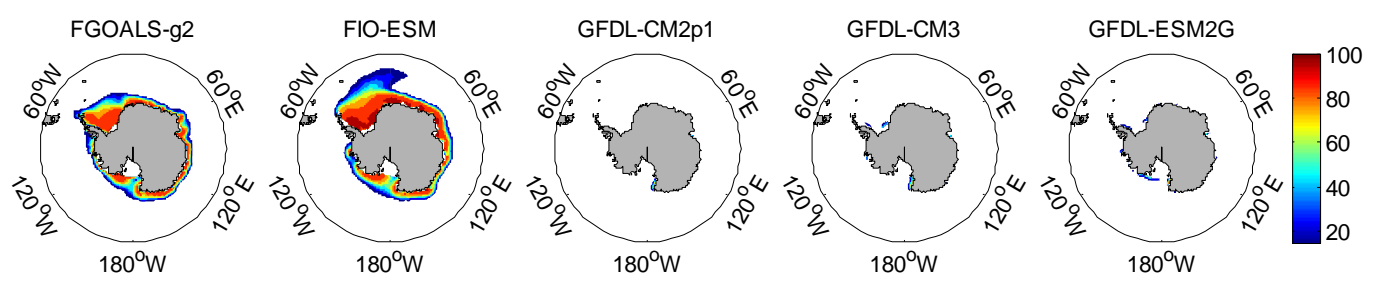

20

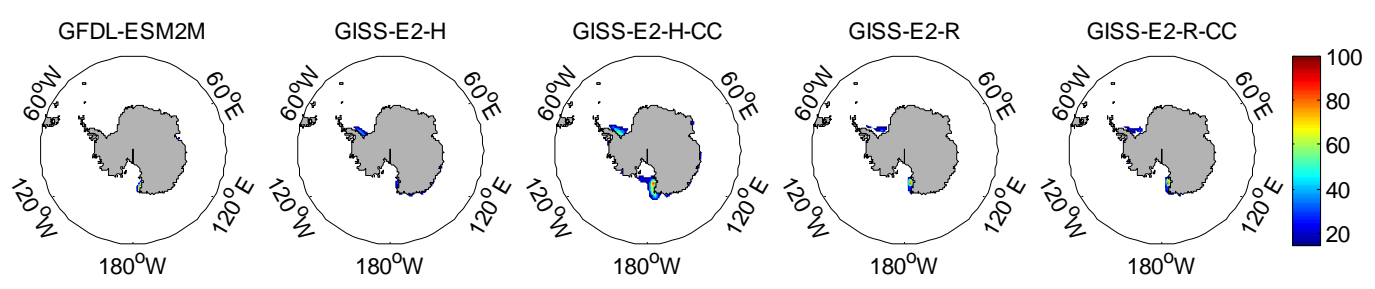

21

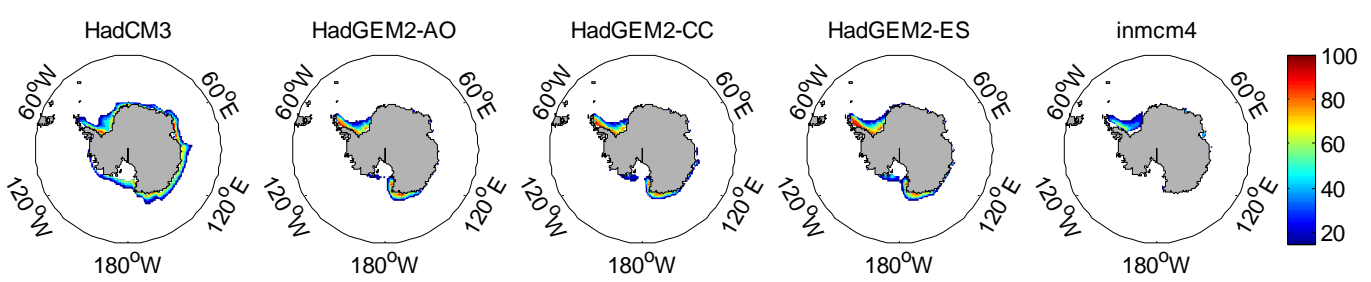


23
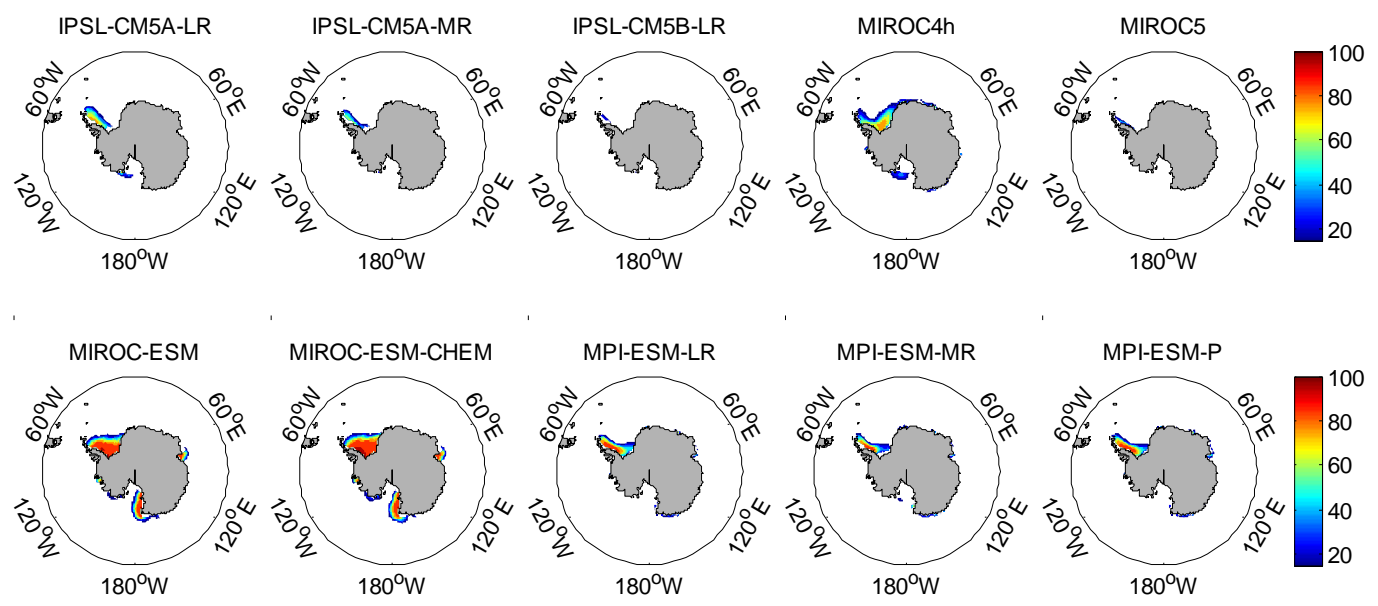

24

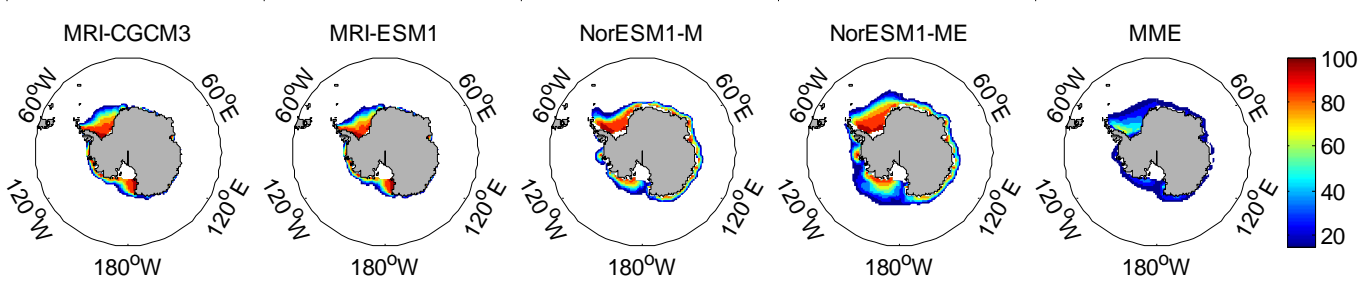

25

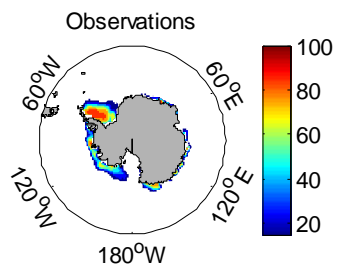

26

27 Figure S3. CMIP5-simulated and satellite-observed Antarctic sea ice concentration in

February during 1979-2005 (units: \%). 
30

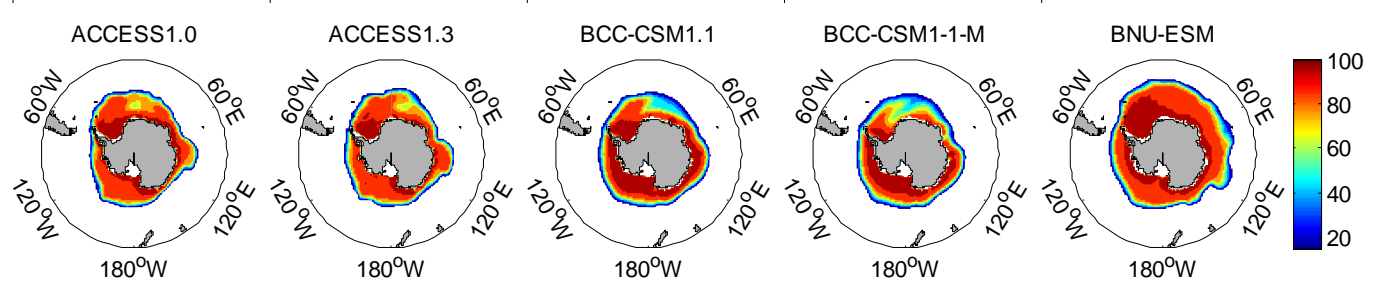

31

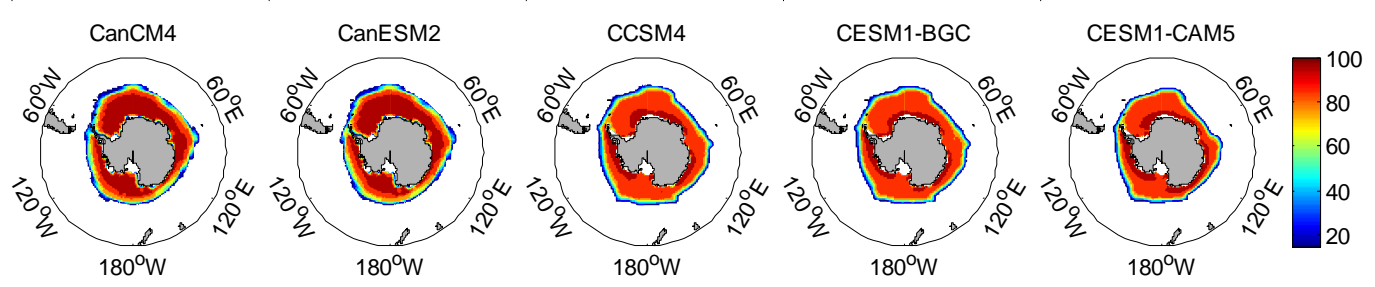

32

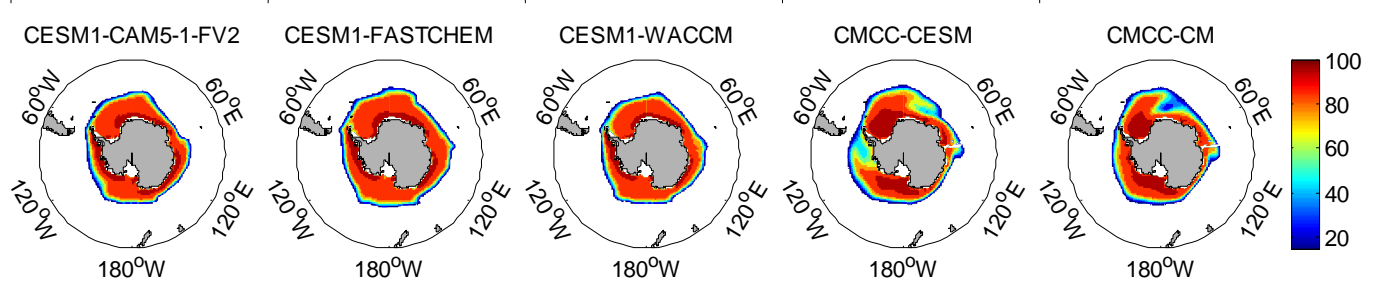

33

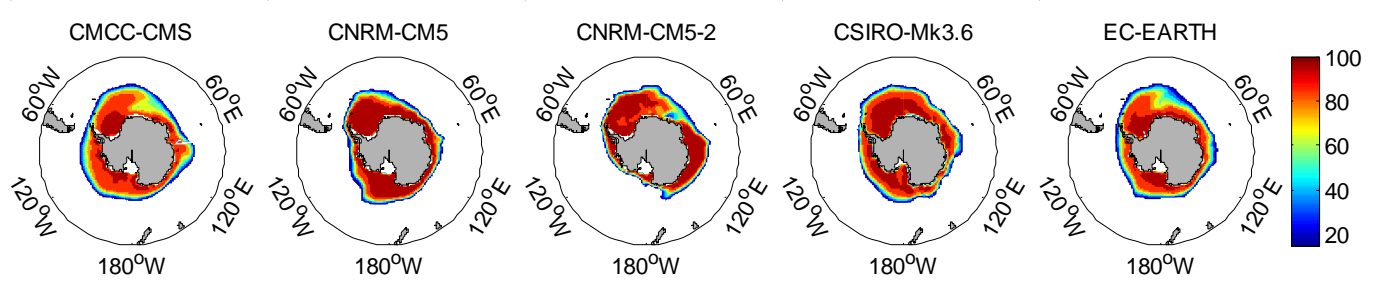

34

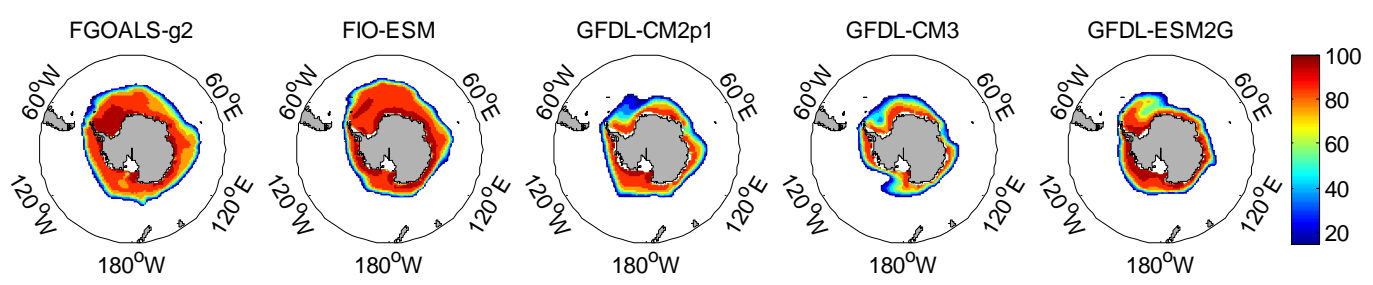

35
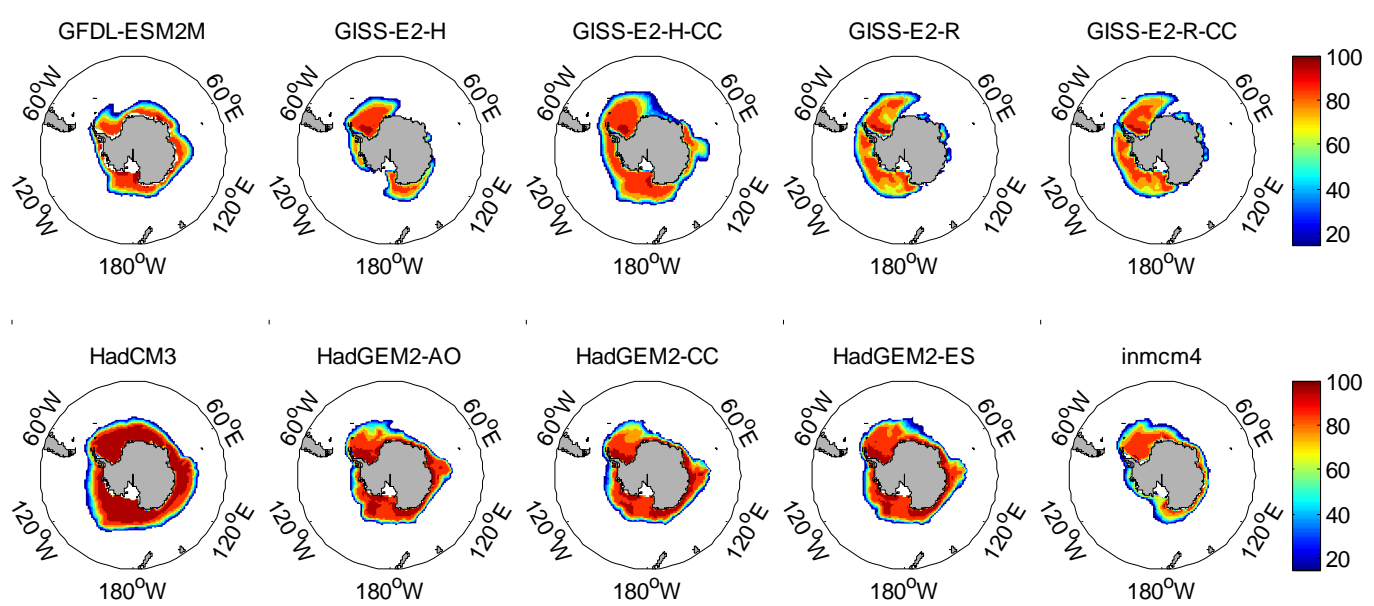
37

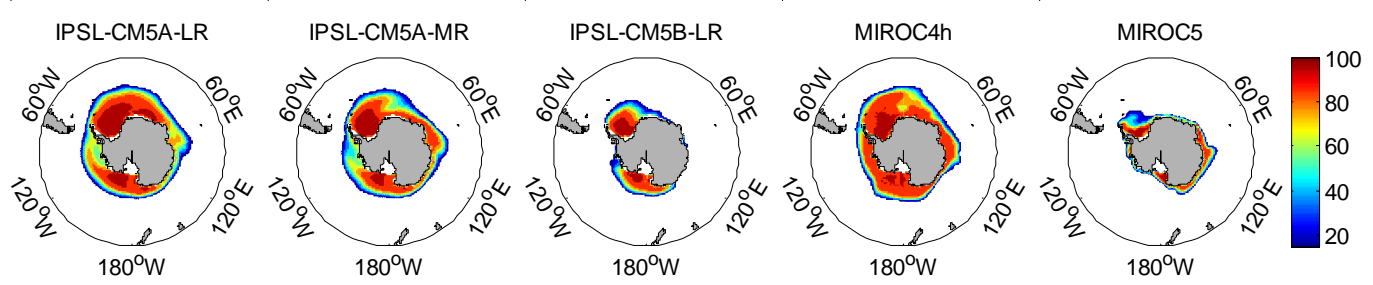

38

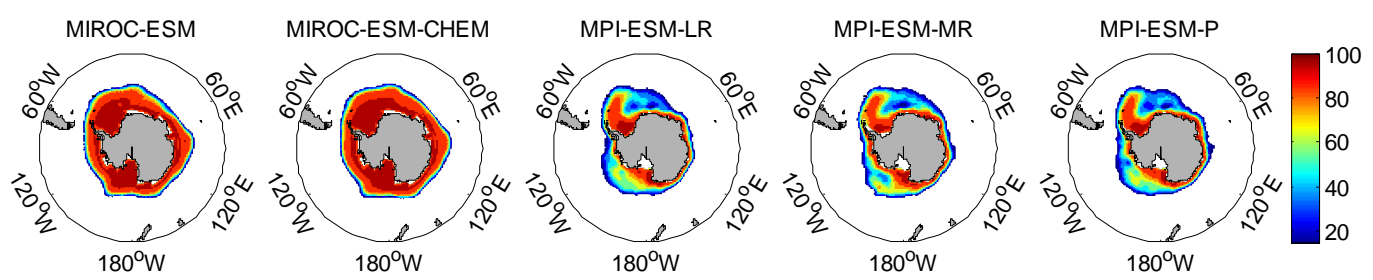

39

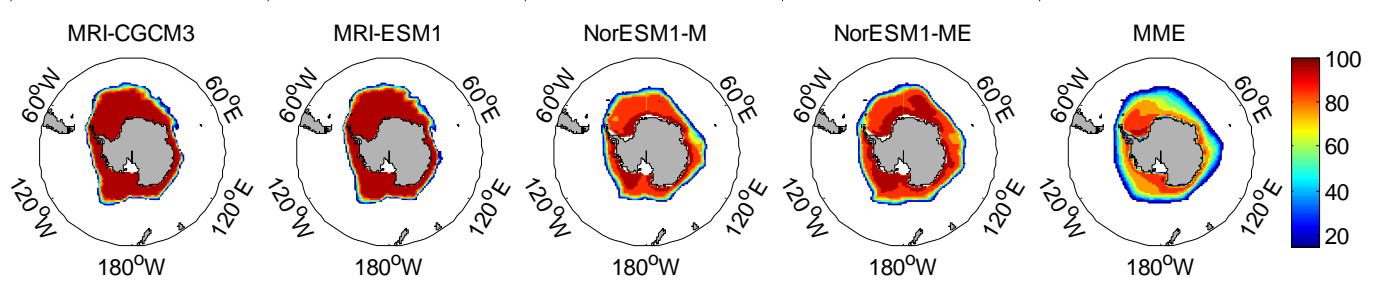

40

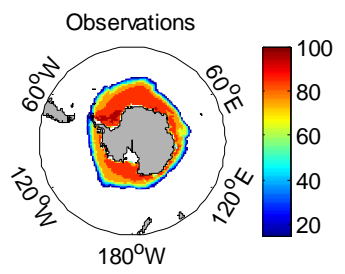

41 Figure S4. CMIP5-simulated and satellite-observed Antarctic sea ice concentration in

42 September during 1979-2005 (units: \%).

43 


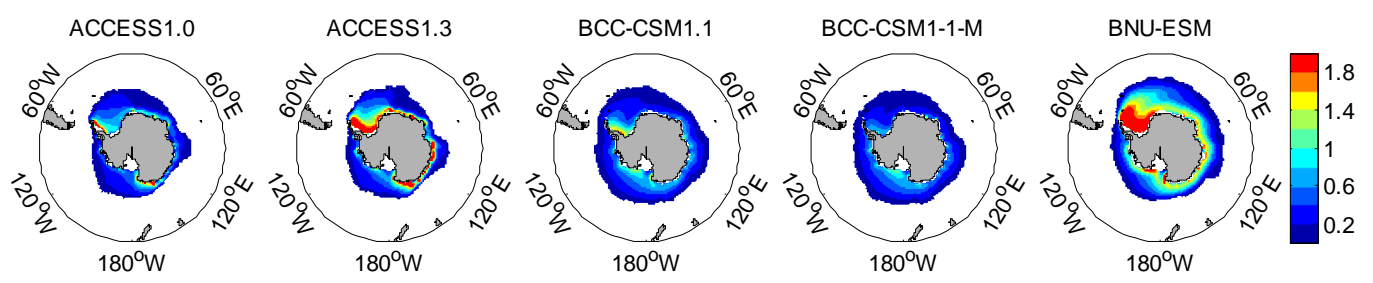

45

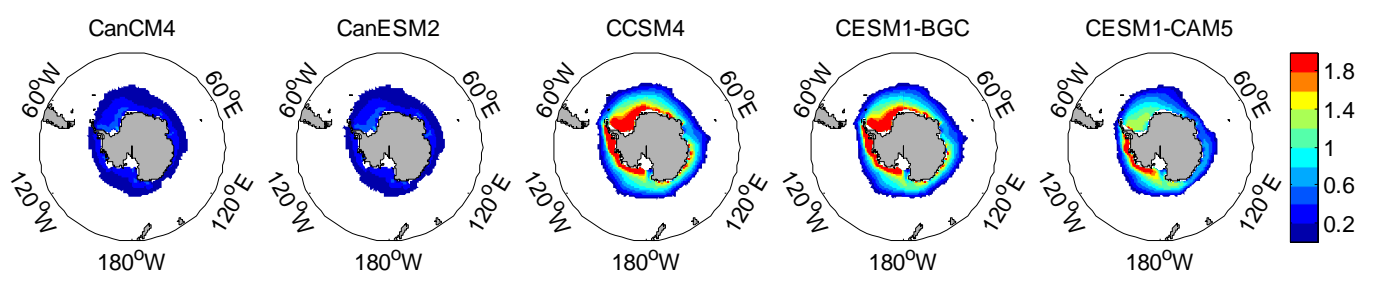

46
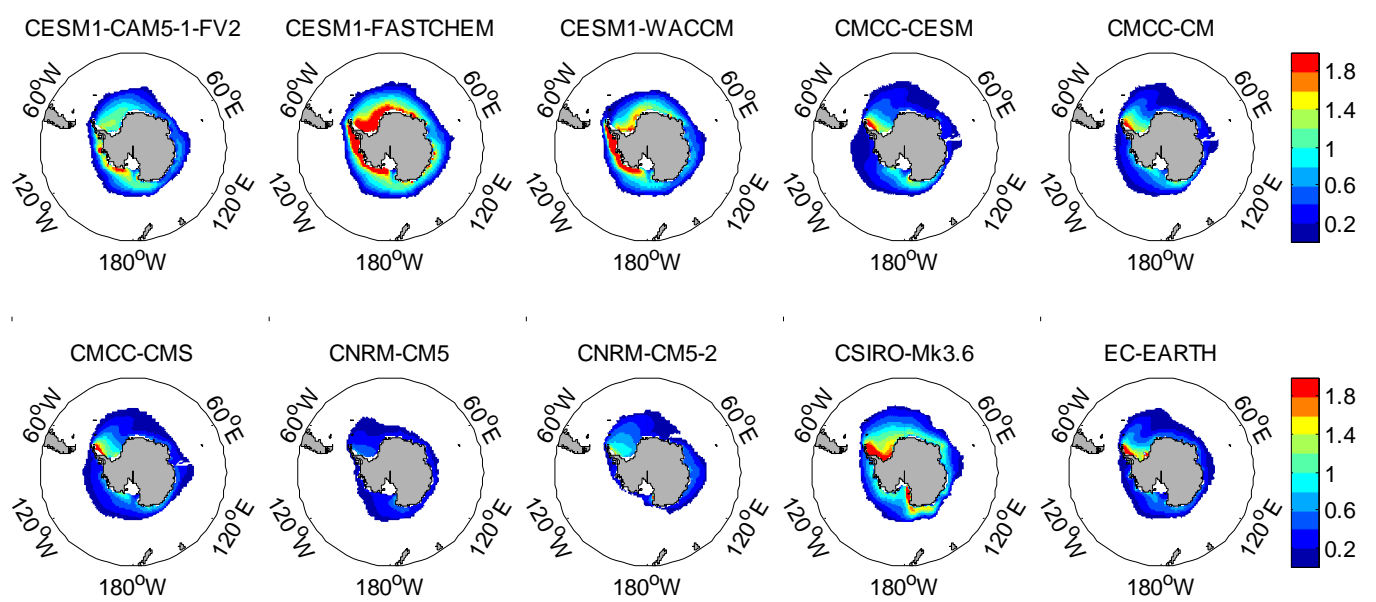

47

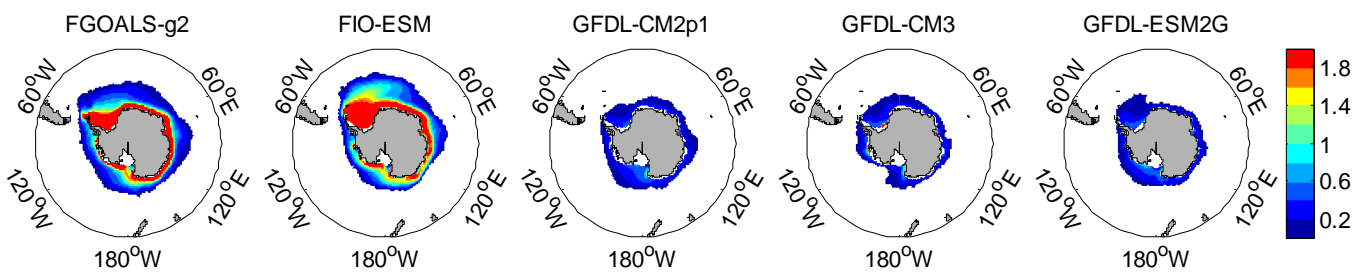

48

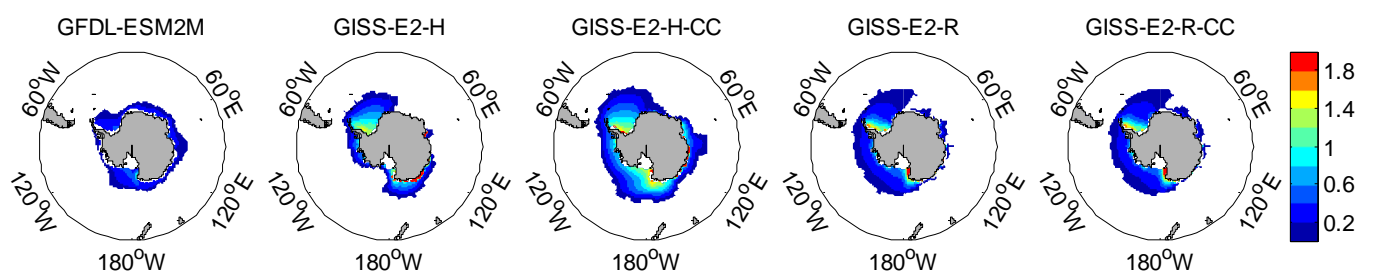

49

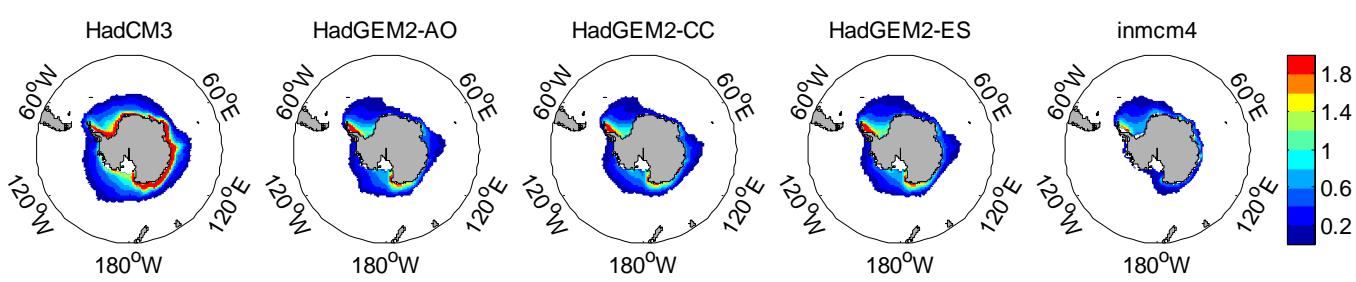


51

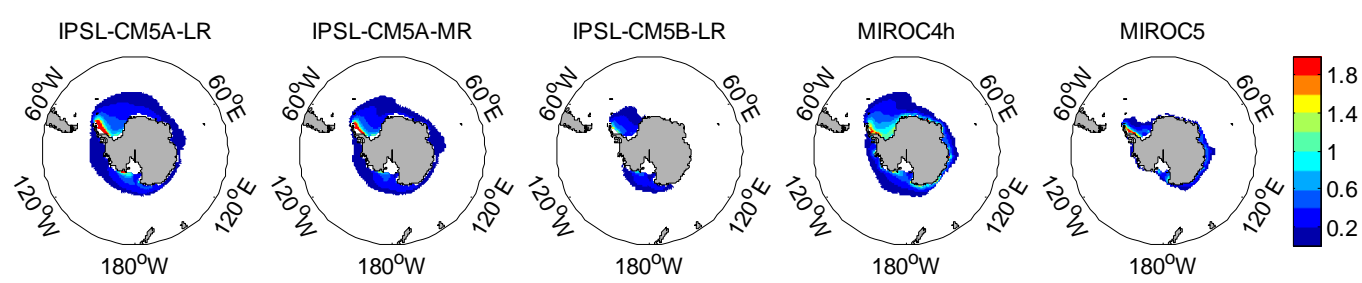

52
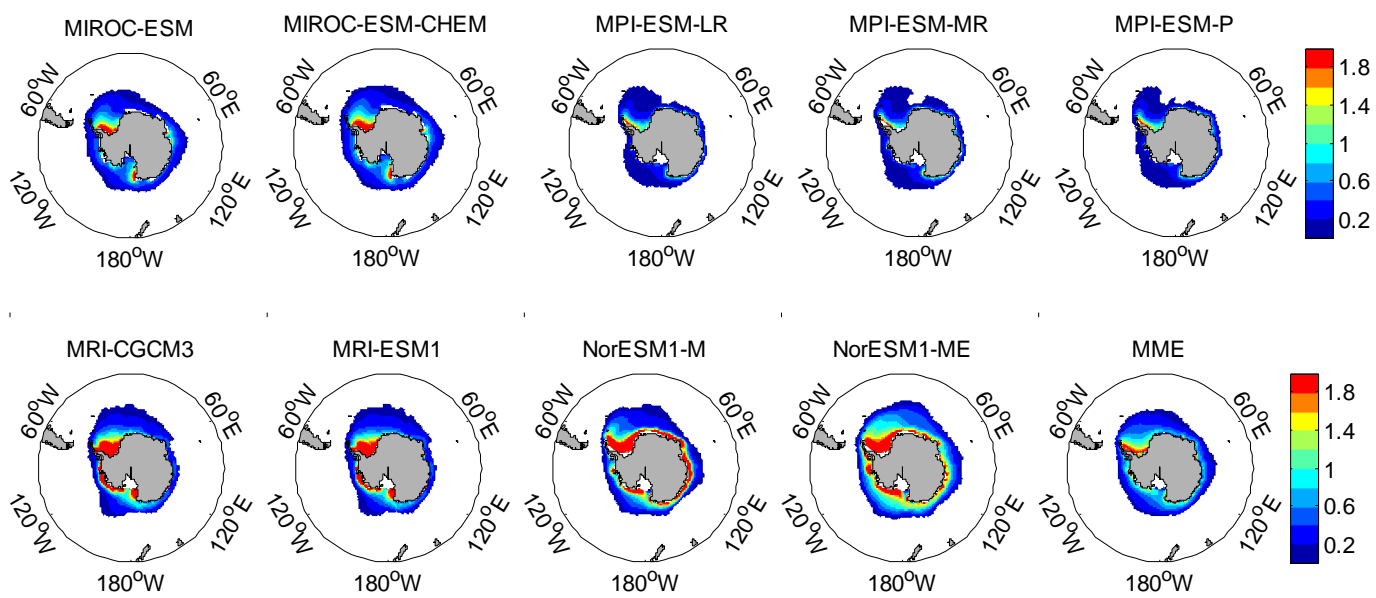

53

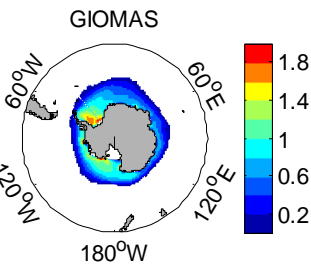

54

55 Figure S5. CMIP5-simulated and GIOMAS Antarctic sea ice thickness during 56 1979-2005 (units: m).

57 
58

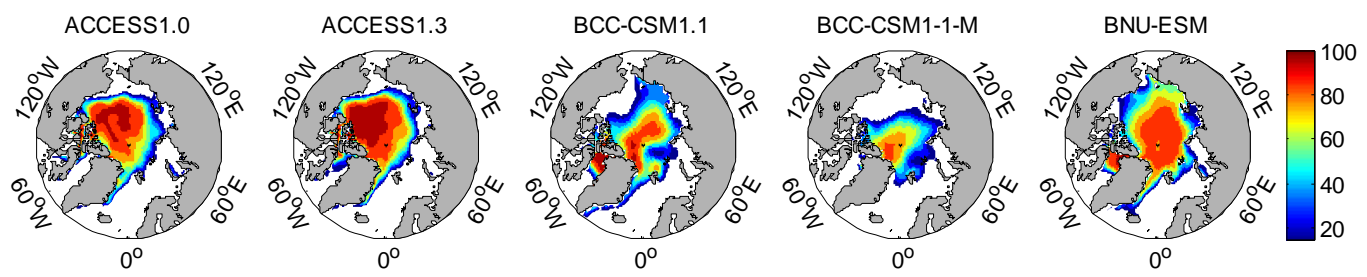

59

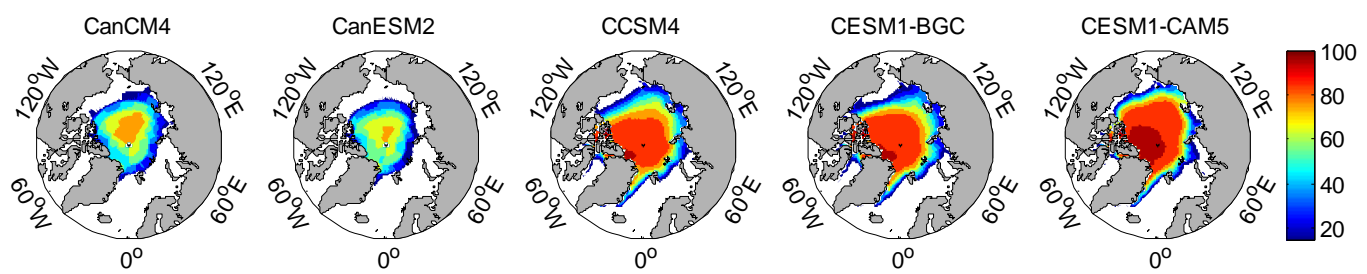

60
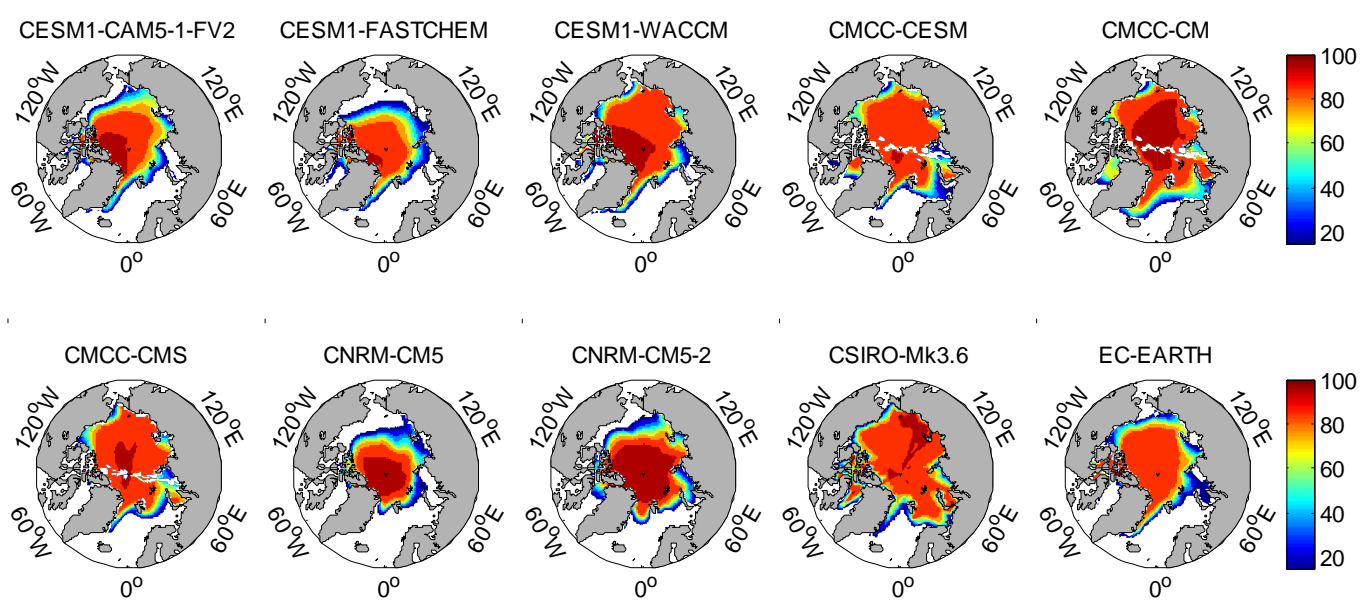

62

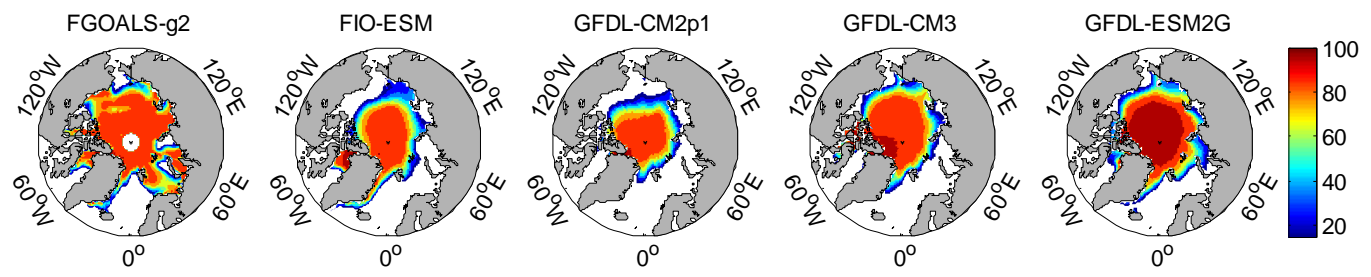

63
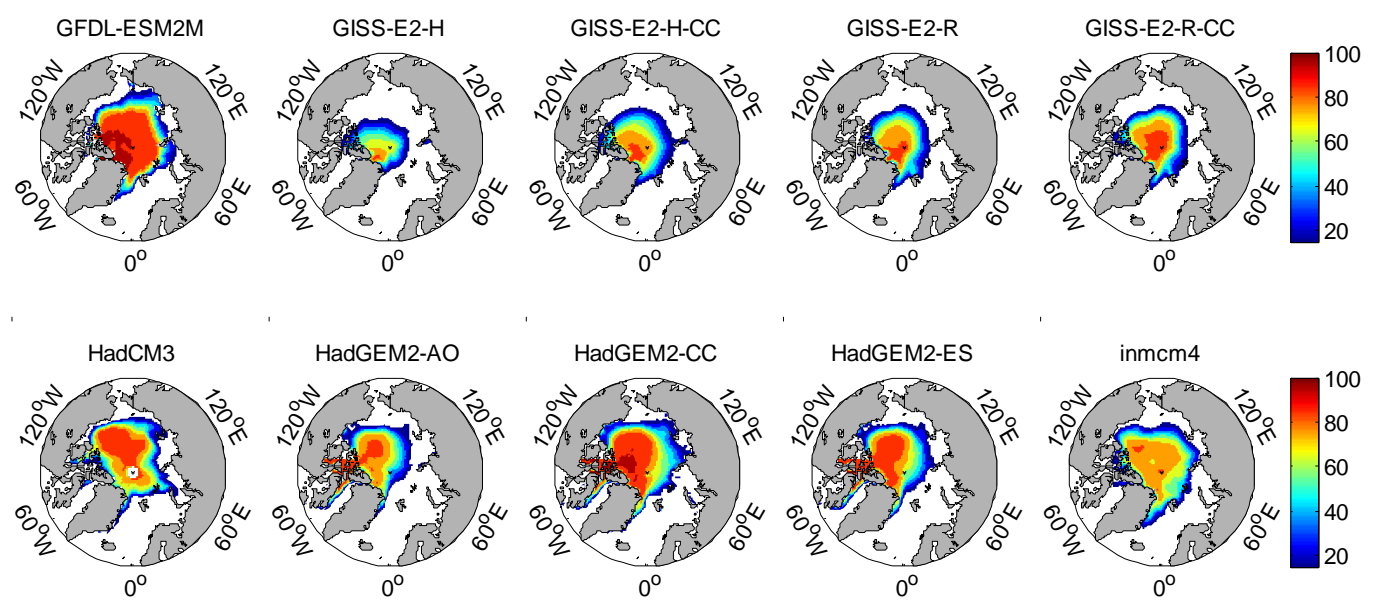
65

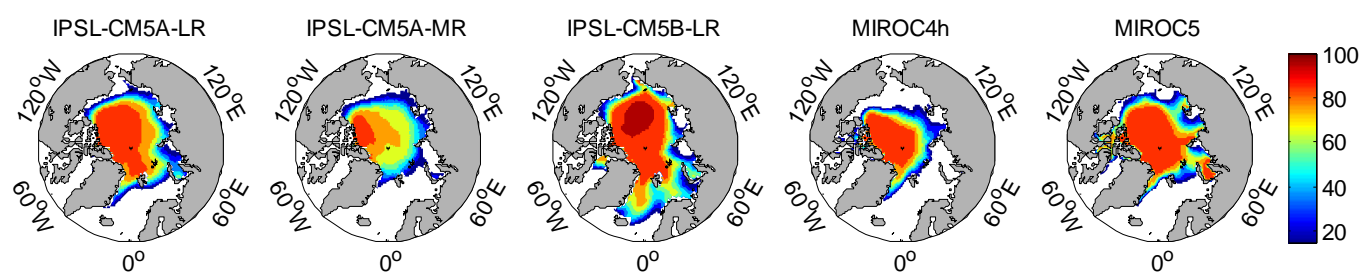

66
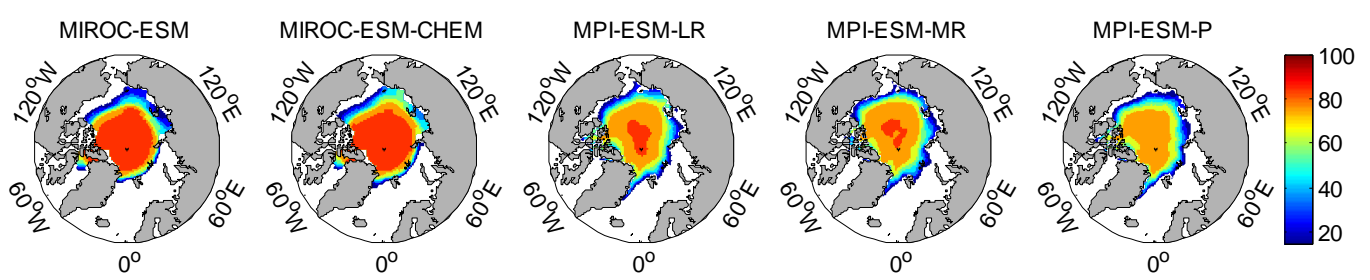

67
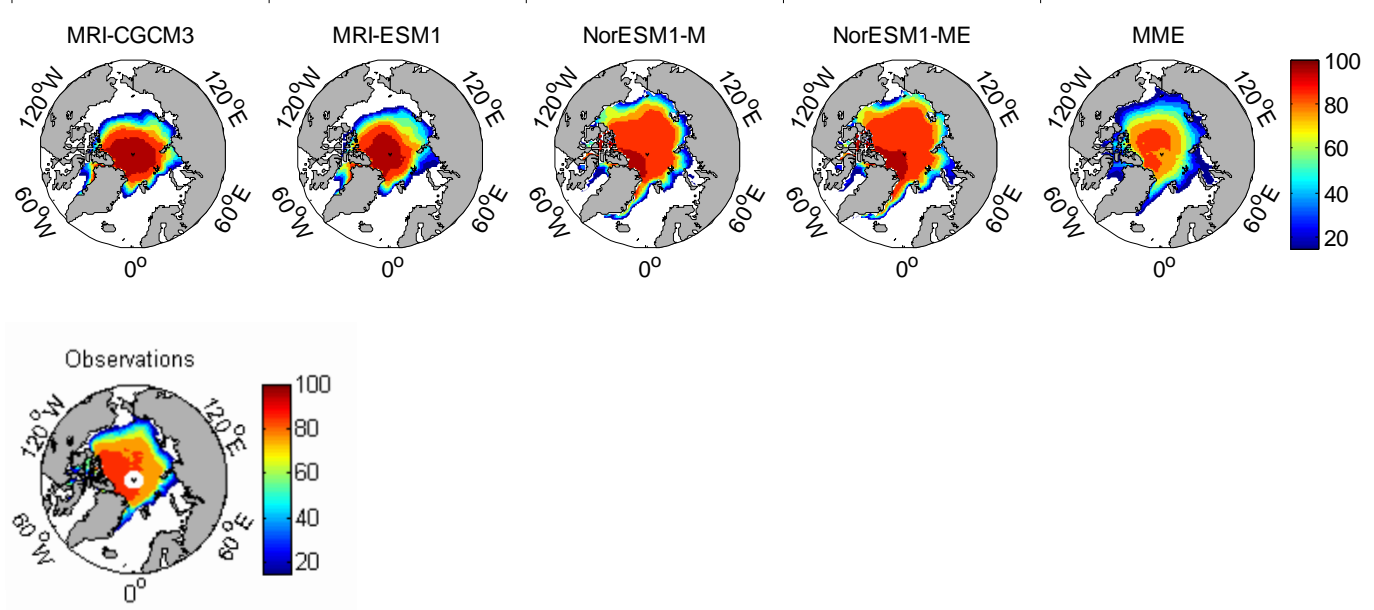

68

69 Figure S6. CMIP5-simulated and satellite-observed Arctic sea ice concentration in 70 September during 1979-2005 (units: \%). 


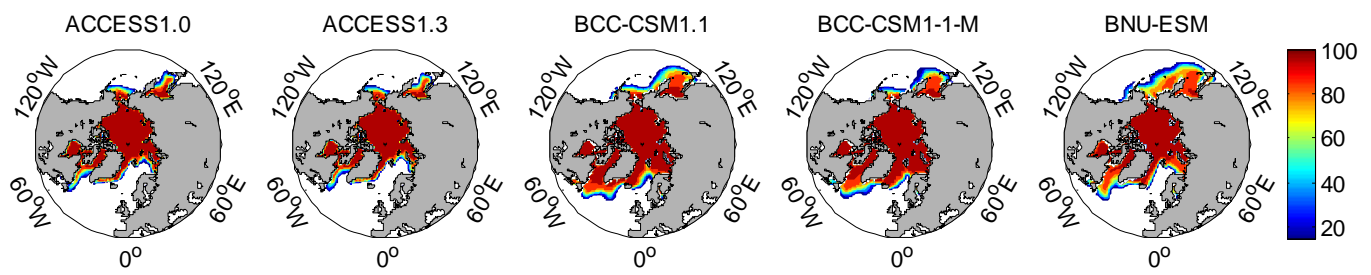

73
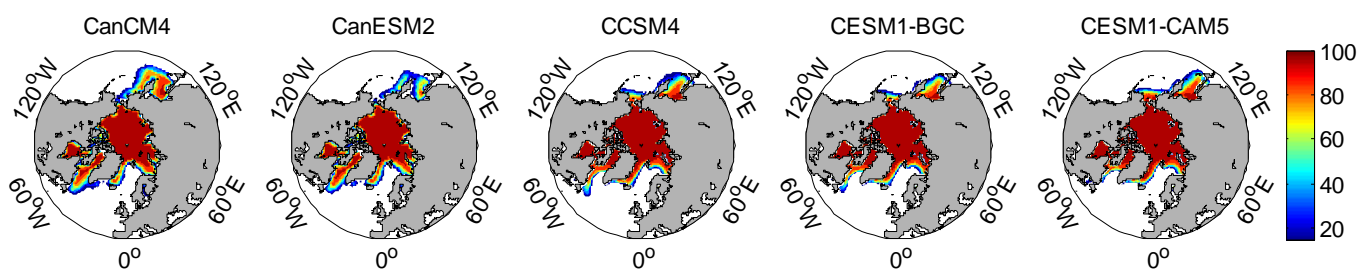

74
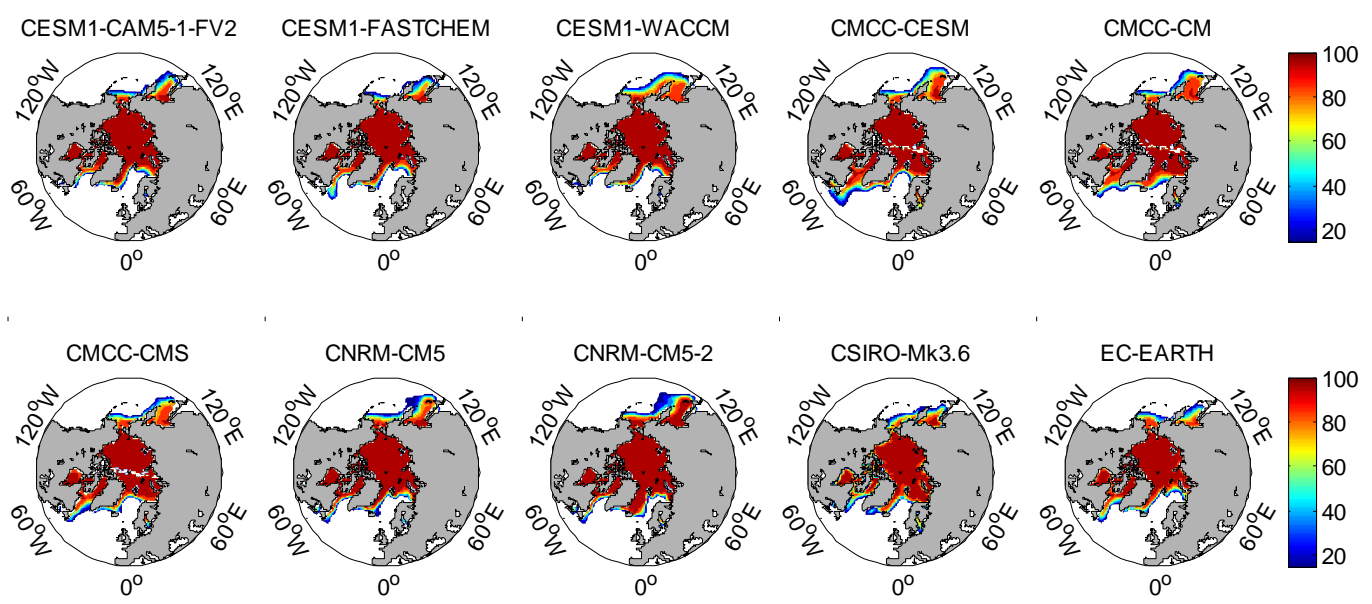

75
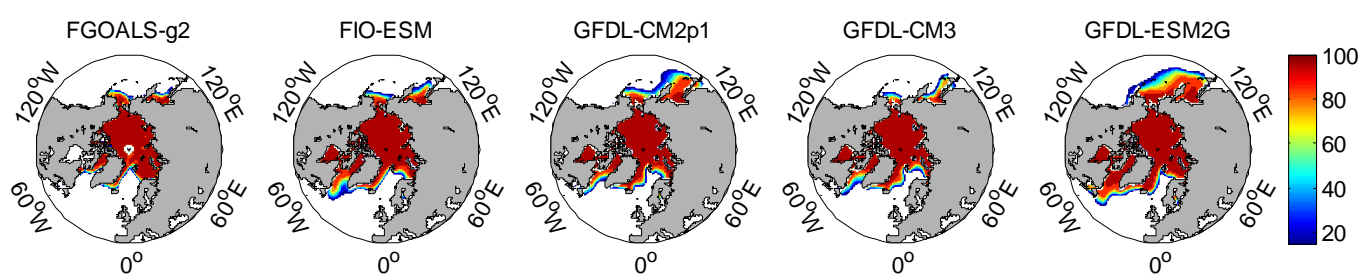

76
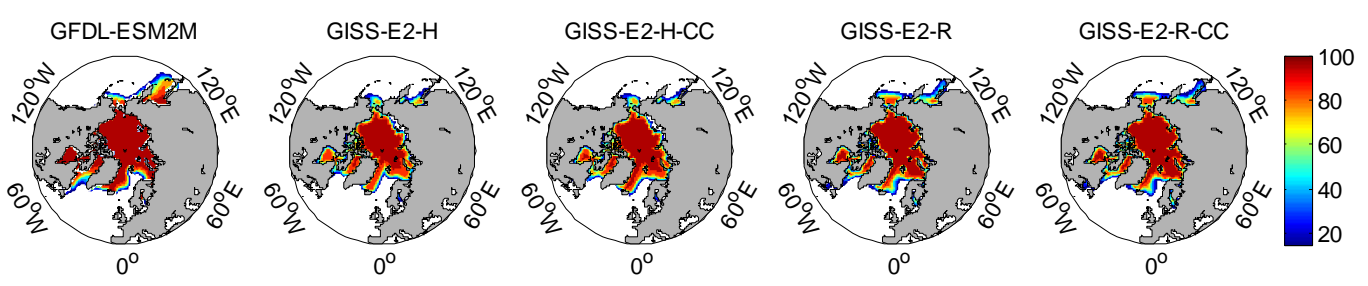

77
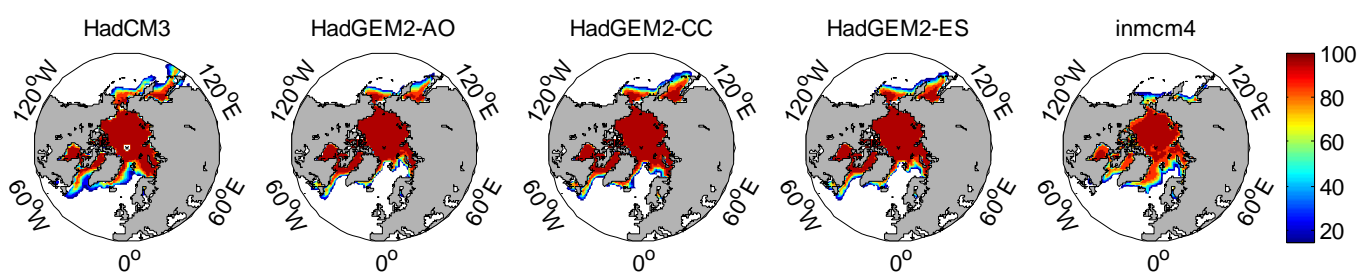
79

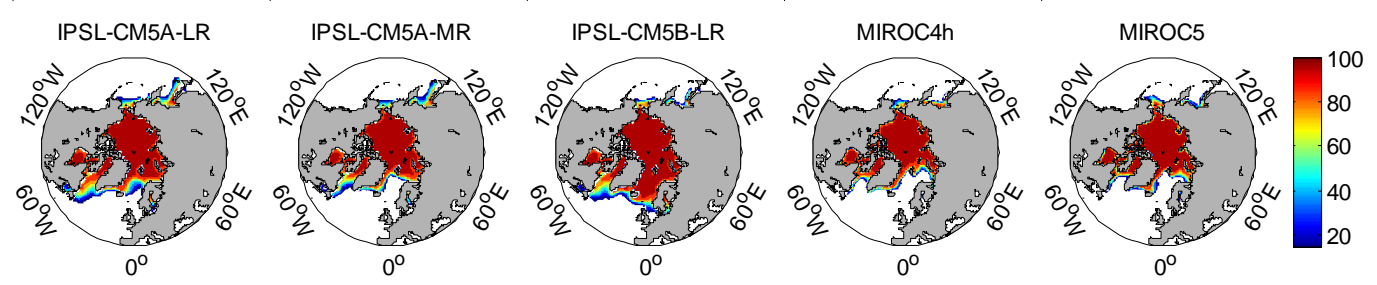

80
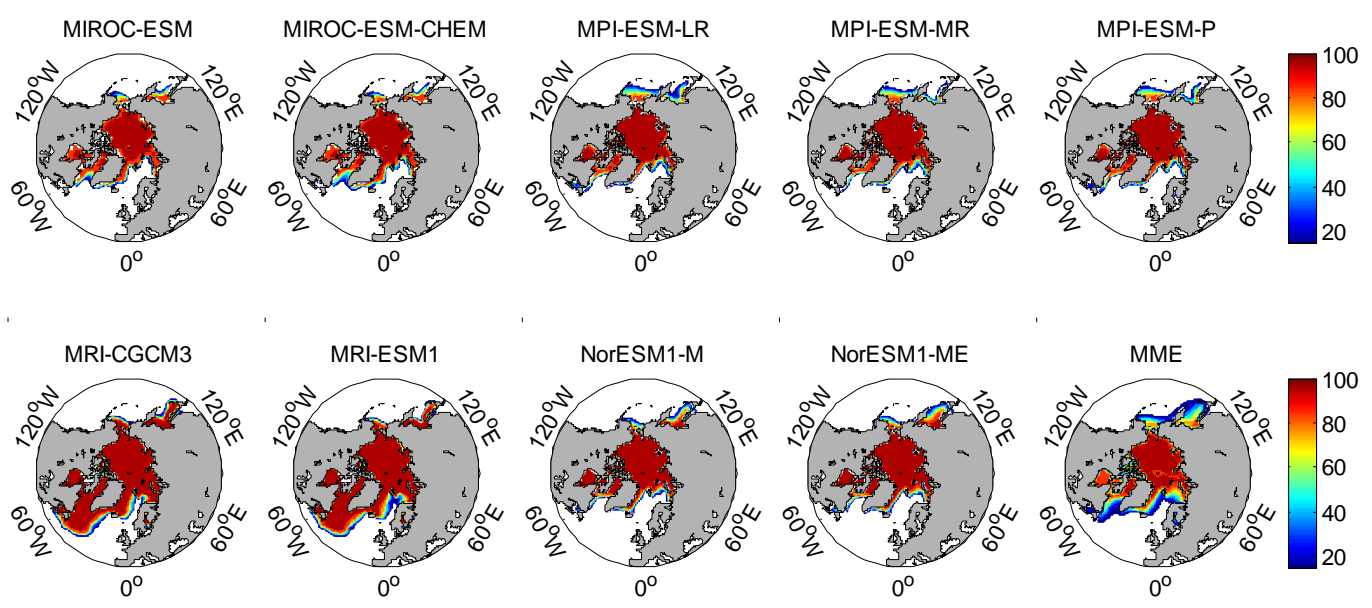

81

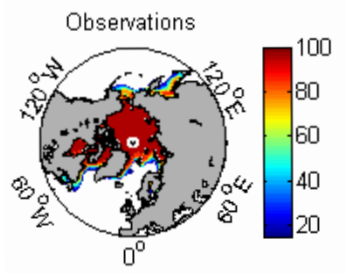

82

83 Figure S7. CMIP5-simulated and satellite-observed Arctic sea ice concentration in 84 March during 1979-2005 (units: \%). 

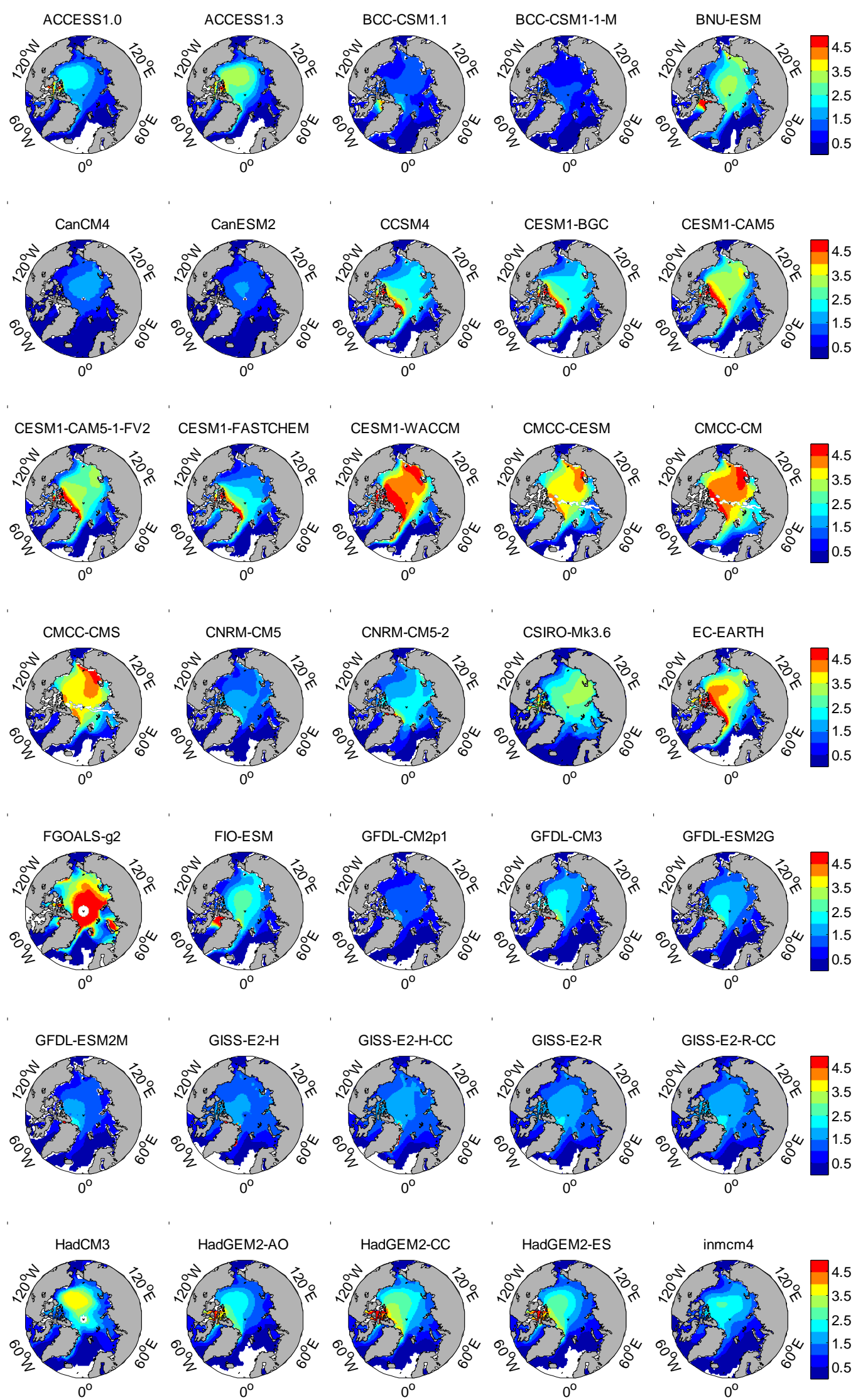

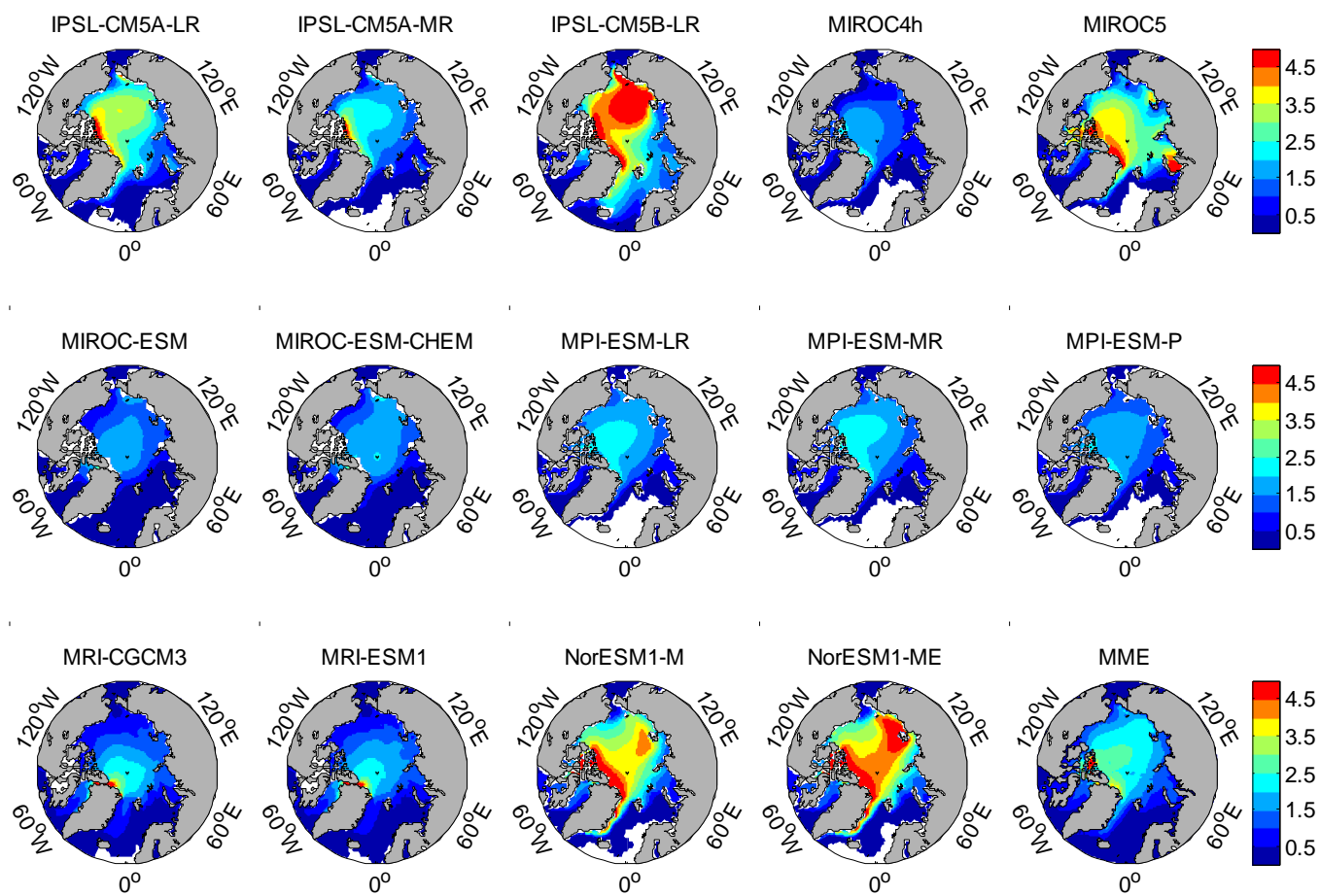

PIOMAS

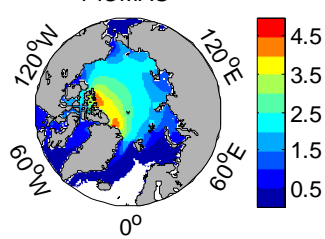

Figure S8. CMIP5-simulated and PIOMAS Arctic sea ice thickness during 1979-2005 (units: m). 